\title{
Article
}

\section{The First City Organizational LCA Case Study: Feasibility and Lessons Learned from Vienna}

\author{
Alexander Cremer ${ }^{1, *(\mathbb{C}, \text { Markus Berger }}{ }^{2}$, Katrin Müller $^{1}$ and Matthias Finkbeiner ${ }^{2} \mathbb{C}$ \\ 1 Siemens AG, 13629 Berlin, Germany; katrin.km.mueller@siemens.com \\ 2 Institute of Environmental Technology, Technische Universität Berlin, 10623 Berlin, Germany; \\ markus.berger@tu-berlin.de (M.B.); matthias.finkbeiner@tu-berlin.de (M.F.) \\ * Correspondence: alexander.cremer@siemens.com
}

Citation: Cremer, A.; Berger, M.;

Müller, K.; Finkbeiner, M. The First City Organizational LCA Case Study: Feasibility and Lessons Learned from Vienna. Sustainability 2021, 13, 5062. https://doi.org/10.3390/su13095062

Academic Editors: Marc A. Rosen and Tiziana Susca

Received: 15 March 2021

Accepted: 29 April 2021

Published: 30 April 2021

Publisher's Note: MDPI stays neutral with regard to jurisdictional claims in published maps and institutional affiliations.

Copyright: (c) 2021 by the authors. Licensee MDPI, Basel, Switzerland. This article is an open access article distributed under the terms and conditions of the Creative Commons Attribution (CC BY) license (https:/ / creativecommons.org/licenses/by/ $4.0 /)$.

\begin{abstract}
Cities are recognized as a major contributor to environmental pressures. Recently, organizational LCA (OLCA) has been found to align well with requirements for city-scale environmental decision support and a novel city-OLCA framework was introduced. City-OLCA combines two relevant aspects: It covers activities beyond public service provision (multi-stakeholder) and emissions beyond greenhouse gases (multi-impact). Its unique approach of acknowledging responsibility levels should help both city-managers and academia in performance tracking and to prioritize mitigation measures. The goal of this work is to test city-OLCA's feasibility in a first case study with real city data from Vienna. The feasibility was confirmed, and results for 12 impact categories were obtained. As an example, Vienna's global warming potential, ozone depletion potential, and marine eutrophication potential for 2016 were 14,686 kt CO 2 eq., 6796 kg CFC-11 eq., and $310 \mathrm{t} \mathrm{N}$ eq., respectively. Our results indicate that current accounting practices may underestimate greenhouse gas emissions of the entire city by up to a factor of 3. This is mainly due to additional activities not covered by conventional standards (food and goods consumption). While the city itself only accounts for $25 \%$ of greenhouse gases, $75 \%$ are caused by activities beyond public service provision or beyond governmental responsibilities. Based on our results, we encourage city managers to include an organizational based LCA approach in defining reduction strategies. This will reveal environmental blind spots and avoids underestimating environmental burdens, which might lead to setting the wrong focus for mitigation.
\end{abstract}

Keywords: life cycle assessment; organizational LCA; cities; decarbonization; energy modeling; monitoring; greenhouse gases; food

\section{Introduction}

Cities must be given special attention in environmental protection. Growing urbanization made them a significant originator of environmental burdens, such as climate change, resource scarcity, or water pollution [1]. At the same time, many (cities and people) are affected by the negative consequences of everyday urban life due to rapid urbanization [2]. Balancing the operational needs of a city (services of general interest) while reducing its environmental pressures pose growing challenges to city managers worldwide [3]. The urge for strategic support is recognized in academia by a growing body of literature on methods to assess urban environmental sustainability (see [4-7]). Shortcomings are seen in (1) a proper definition of system boundaries, (2) a holistic point of view, and (3) measuring environmental effects (missing impact assessment). This summarizes the main research gaps that are shared across several comprehensive review papers, for example [8-10].

Product life cycle assessment (LCA) has already been identified as a promising candidate to overcome these research gaps [11]. While many of the recent studies in this field focus on comparing environmental performance among different cities (e.g., [12]), we aim at measuring transformations within a given city. 
In our recent work [13], we therefore suggested using an organizational equivalent of the product functional unit-following the proposal made for organizational LCA (OLCA). OLCA was not subject to either of the previously mentioned reviews nor has it ever comprehensively been applied to an urban context. This is remarkable since cities obviously represent an organizational structure-at least from an administrative point of view. In [13], we were able to show that OLCA aligns well with requirements for city-scale environmental decision support and that its organizational view might be of particular interest for city managers.

This novel city-OLCA approach was developed to support local governments in tracking their environmental performance and to prioritize mitigation measures. Compared with other methods, such as flow analysis or carbon footprinting, city-OLCA combines two relevant aspects. It covers activities beyond public service provision (multi-stakeholder) and emissions beyond greenhouse gases (multi-impact).

So far, this approach had only been applied to a hypothetical city to demonstrate the capabilities of city-OLCA [13]. It is now performed with real-world data from Vienna to test the feasibility according to available data and existing city structures, as well as to test city strategies on mitigation measures and its holistic impact. Additionally, we compare our results against official greenhouse gas monitoring schemes: Vienna's own climate program (KliP) and a national breakdown (BLI) by the federal environmental agency [14,15]. Vienna has been selected as an example of an open data governance approach as well as for its strong public service orientation. The reference year chosen is 2016, as data consistency was considered best across all sources. To summarize, the paper addresses two main research questions: 1. What does a real-world case study, here for the example of Vienna, of the cityOLCA method reveal in terms of applicability and relevance? 2. How do the city-OLCA results compare to existing environmental assessment schemes applied by Vienna?

Section 2 introduces the city-OLCA framework (Section 2.1) and its transfer to Vienna (Section 2.2). Information on the reporting organization, system boundary, and reference flow is given (Section 2.3), as well as chosen impact categories and software used (Section 2.4). Section 3 presents the data and data sources used and explains key modeling approaches. Results are shown in Section 4, referring to global warming (Section 4.1), impacts beyond greenhouse gases (Section 4.2), and the contribution of life cycle stages (Section 4.3). Section 5 discusses Vienna specific case study results (Section 5.1), examines methodological findings (Section 5.1, Section 5.2, Section 5.3) and deducts the transferability of results and methods to other cities (Section 5.4). Section 6 concludes key findings obtained in this work and provides an outlook for future research. A list of abbreviations is provided in Appendix A.

\section{Methodology}

\subsection{The City-OLCA Framework}

The city-OLCA framework according to [13] distinguishes between four assessment levels (Figure 1). Level 1 considers activities related to the public service provision by city owned companies. Level 2 also includes public service provision by private companies. Level 3 considers (a) activities indirectly influenced by administrative decisions and (b) all other activities taking place within the city boundary. A detailed description of the framework and methodological background can be found in [13]. In the following section, this framework is applied to the case study of Vienna. 


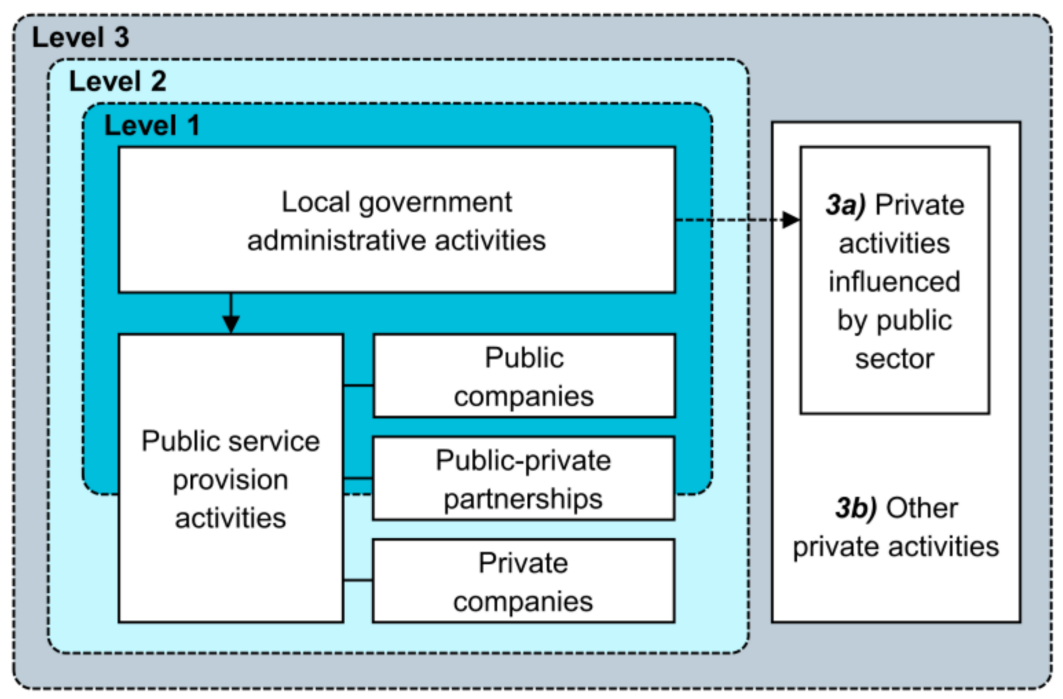

Figure 1. City-OLCA framework according to [13]. Level 1 considers public service provision by city-owned companies. Level 2 considers public service provision by contracted companies. Level 3 considers activities beyond public service provision.

\subsection{Vienna's City Characteristics and Its Organizational Structure According to the City-OLCA Framework}

Vienna frequently leads rankings of the most livable cities. In 2019, the city was named best city for quality of life by [16] for the tenth year in a row-followed by Zurich and Vancouver. According to Vienna's Mayor, a key success factor was that the city did not follow the privatization trend in the 1990s. Hence, all services of general interest are provided by the public sector [17].

The generic framework presented in Section 2.1 was applied to the concrete situation in Vienna. While the overall framework proves useful and applicable, it also became apparent that individual cities can have their peculiarities. Figure 2 shows the organizational structure of Vienna according to the city-OLCA framework. Activities in each level are described below.

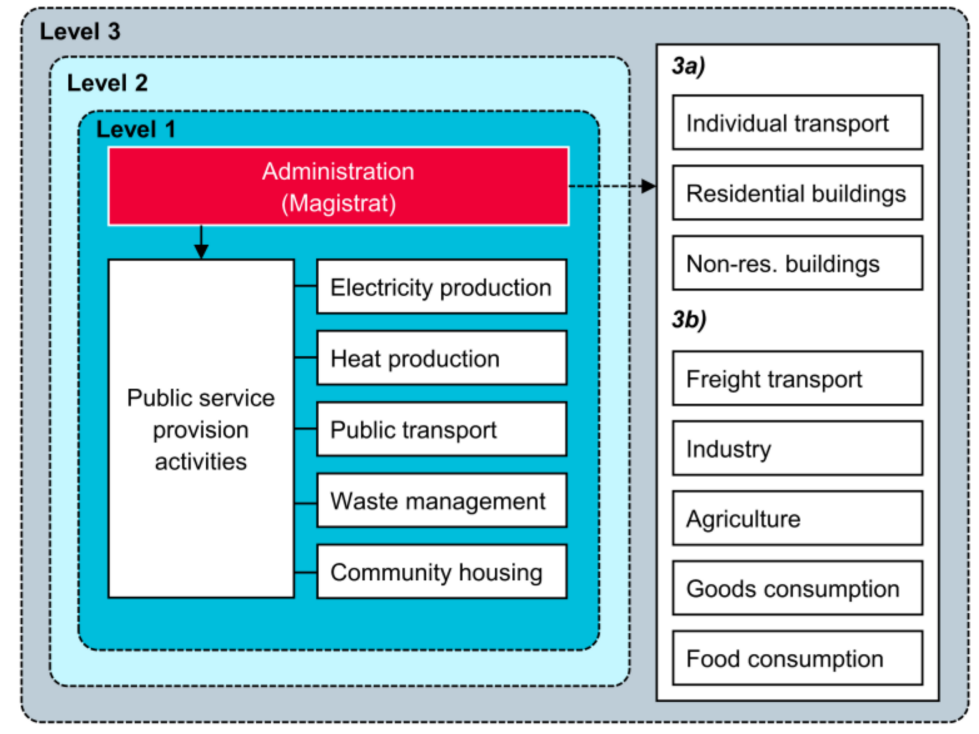

Figure 2. Vienna's organizational structure according to city-OLCA. A total of 14 activities were considered. As the city provides all public services with city-owned companies, level 2 activities are empty. 


\subsubsection{Level 1: City-Owned Public Service Provision}

Level 1 comprises the administrative activities, electricity supply, district heat supply, public transport, waste management, and community housing. All of these services are provided by the city itself or city-owned companies.

\subsubsection{Level 2: Contracted Public Service Provision}

All public services are included in level 1. Vienna has no level 2 activities.

\subsubsection{Level 3: Activities beyond Public Service Provision}

Level 3 is divided into two parts. Level 3a comprises activities indirectly influenced by the local government and that intensively use the city's infrastructure. This includes individual transportation, residential buildings, and non-residential buildings.

Level $3 \mathrm{~b}$ comprises activities beyond governmental responsibilities. In our example, this includes freight transportation, industry, agriculture, and goods and food consumption by citizens.

Whether activities fall under level $3 a$ or level $3 b$ is not always clear cut. Our chosen distribution may differ from that of other practitioners. The total result is, however, not affected by this.

\subsection{Reporting Organization, System Boundary and Reporting Flow}

An OLCA requires defining a reporting organization, system boundary, and reporting flow [17]. The reporting organization is the city of Vienna, represented by the local government. The system boundary is represented by assessment levels as described above. In each assessment level, we include the production and use phase of activities. The reporting flow is a measure of the outputs of the reporting organization and serves as a basis for life cycle inventory. In city-OLCA, the reporting flow consists of the activities in each assessment level as displayed in Table 1:

Table 1. Reporting flows and values for each assessment level considered in Vienna's city-OLCA. Details are provided in Section 3.

\begin{tabular}{|c|c|c|c|}
\hline Level & Reporting Flow & 2016 Value & Sources \\
\hline \multirow{6}{*}{ Level 1} & Administration & 30,219 Employees & {$[18,19]$} \\
\hline & Electricity production & 5747 GWh/a & {$[20,21]$} \\
\hline & Heat production & $6205 \mathrm{GWh} / \mathrm{a}$ & {$[20,22]$} \\
\hline & Public transport & $8,285,773,793 \mathrm{pkm} / \mathrm{a}$ & [23-25] \\
\hline & Waste management & $763,325 \mathrm{t} / \mathrm{a}$ & {$[26,27]$} \\
\hline & Community housing & $18,344,800 \mathrm{~m}^{2}$ & [28] \\
\hline Level 2 & $\mathrm{~N} / \mathrm{A}$ & $\mathrm{N} / \mathrm{A}$ & \\
\hline \multirow{3}{*}{ Level 3a } & Individual transport & $10,983,467,586 \mathrm{pkm} / \mathrm{a}$ & [23-25] \\
\hline & Residential buildings & $55,034,400 \mathrm{~m}^{2}$ & [20] \\
\hline & $\begin{array}{l}\text { Non-residential } \\
\text { buildings }\end{array}$ & $35,328,000 \mathrm{~m}^{2}$ & [20] \\
\hline \multirow{5}{*}{ Level 3b } & Freight transport & $4,242,399 \mathrm{tkm} / \mathrm{a}$ & [25] \\
\hline & Industry & Heat \& Power ${ }^{1}$ & [20] \\
\hline & Agriculture & Heat \& Power \& Fuel ${ }^{1}$ & [20] \\
\hline & Goods consumption & $3887 \mathrm{kt} \mathrm{CO}_{2}$ eq. & {$[29,30]$} \\
\hline & Food consumption & $2333 \mathrm{kt} \mathrm{CO}$ eq. & {$[29,30]$} \\
\hline
\end{tabular}

${ }^{1}$ Industry and agriculture were modeled based on energy and fuel input as described in Section 3.5, which does not support a single aggregated value to be displayed in this table.

\subsection{Life Cycle Impact Assessment and Software Used}

For the life cycle impact assessment, we chose the ReCiPe 2016 midpoint (E) V1.04 methodology [31]. In total, the following 12 midpoint impact categories were considered: Global warming, stratospheric ozone depletion, ionizing radiation, ozone formation 
(human health), fine particular matter formation, terrestrial acidification, marine eutrophication, terrestrial ecotoxicity, human carcinogenic toxicity, mineral resource scarcity, and fossil resource scarcity. The Vienna city-OLCA model was computed with SimaPro (version 8.5) [32] and the Ecoinvent database (version 3.4) [33]. The parameterized city-model consisting of 194 nodes (processes and materials) is shown in Figures S1-S4.

\section{Material and Modeling Approach}

An overview on modeling logic and data used is given in the following sections. Wherever possible, we summarized all activities that underlie the same modeling logic in one group.

\subsection{Energy}

\subsubsection{Electricity}

Electricity and heat that is produced by the city itself is classified as public service provision. These energy-related emissions are located at the city level. For 2016, the production of electricity amounts to 5747 GWh [20]. In Vienna, electricity consumption exceeds production by approximately $20 \%$. This additional electricity is attributed to the building and transport sectors.

Here, the Austrian average grid mix is taken. We have subtracted Vienna's share of the national grid mix to avoid double counting (the national grid mix already has an $8.7 \%$ share of Vienna included [21]). See Section 5.3 for a discussion on an alternative approach.

\subsubsection{District Heating}

Vienna produces approximately 6205 GWh district heat per year-mainly through gas fired combined heat and power (CHP) plants [20]. As CHP plants produce both heat and power, we modeled heat and power considering the plant's multiple output.

The composition of district heat is shown in Figure S5. Data for the district heating mix are taken from [20,22].

Overall emissions considered for both electricity and heating include the operation, maintenance, and production of the energy plants as well as infrastructure activities.

\subsection{Transport}

The transport sector is modeled based on total transport demand in person- $\mathrm{km}$ and ton-km, respectively. Within personal transportation, city-OLCA distinguishes between individual and public transportation. In 2016, individual transportation demand was 10.98 billion pkm (or $57 \%$ ). Public transportation demand was 8.29 billion pkm (or $43 \%$ ). Figure 3 shows the modal split of personal transportation used in this work:

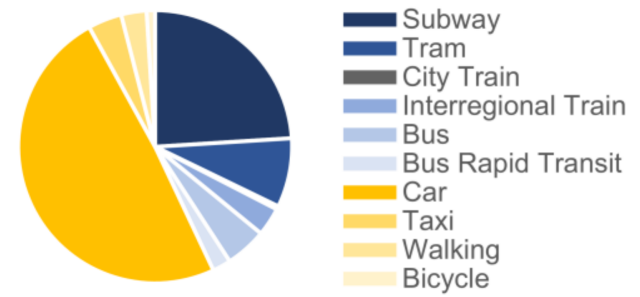

(a)

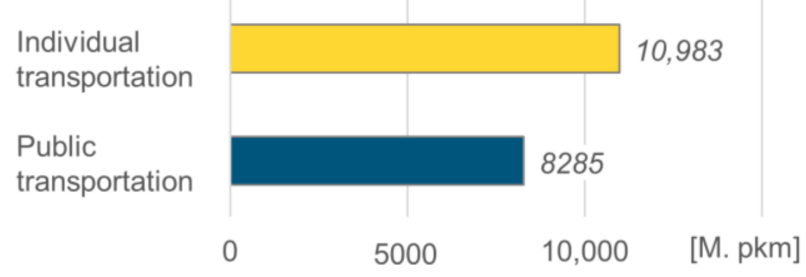

(b)

Figure 3. Personal transport demand data for Vienna for 2016: (a) Modal split based on person-km, (b) total personal transport demand for individual and public transportation in million person-km. Values according to [23-25].

Data were taken from [23-25]. Transport-related emissions are calculated at vehicle level. Each mode's capacity utilization and specific energy demand results in total vehicle$\mathrm{km}$ driven and fuel/power consumed. Modes with a high-capacity utilization (e.g., buses) 
need less vehicle-km to serve the same amount of person- $\mathrm{km}$ than modes with a lowcapacity utilization (e.g., cars).

Overall emissions considered include the operation, maintenance, and production of the vehicle as well as infrastructure-related emissions (road construction).

\subsection{Buildings}

We separated four building types in Vienna: (1) Administrative buildings, (2) community housing buildings, (3) average residential buildings, and (4) non-residential buildings.

Electricity-related emissions for each building type are calculated as described in Section 3.1. They only comprise additional electricity taken from the national grid, as the other amount of energy used in buildings is generated by city-owned companies and accounted as emissions of own operations in the energy sector.

Heating-related emissions comprise emissions related to point sources (e.g., oil heating). Each building type is linked to a specific heating mix representing its on-site heating situation. The different heating mixes are shown in Figure S6.

Data for floor space and energy demand were taken from [18-20,25,28].

For the production of the buildings, an average apartment building was assumed and scaled per total square meters of each building type. The life cycle inventory from [34] was taken as a reference with an assumed building lifetime of 130 years.

Overall emissions considered include the operation, maintenance, and production of the buildings as well as supporting activities (on-site delivery of building materials, etc.).

\subsection{Waste Management}

Waste management is modeled based on the municipal waste generation and treatment pathways. The majority ( $65 \%$ ) of a total of $1.138 \mathrm{Mt}$ waste is sent to thermal treatment, $19 \%$ is recycled, $11 \%$ is treated biologically, and $5 \%$ is landfilled.

Data were taken from [26] with waste fractions reported in [27] and can be found in Figure S7.

Overall emissions considered include the operation and production of the waste facility, as well as the municipal collection service.

\subsection{Industry and Agriculture}

Both sectors include the energy input (electricity and heat) based on [20]. Agricultural machinery is modeled based on the reported fuel consumption. With an average fuel consumption, we calculated the total ton-km of tractor use.

Overall emissions considered include power and heating of buildings, production, operation, and maintenance of machinery.

\subsection{Goods and Food Consumption}

Emissions related to the consumption of goods and food are based on time-use surveys as presented by [29]. In their study, the authors presented a way of linking data from the Austrian time-use and household budget surveys with the Eora multi-region input-output (MRIO) table for 2009-2010. Eora is a global supply chain database that provides time series of input-output tables with matching greenhouse gas emissions [35].

Each household activity obtains a per hour emission factor. For example, running shoes that are worn and beverages that are consumed during workout are considered pro rata.

In this work, we used the breakdown for Vienna by [30] and extrapolated it to 2016 based on population growth (assuming average consumption patterns did not change). We then excluded all building- or transport-related energy consumption to avoid double counting.

Overall emissions considered include the entire value chain of consuming goods and food in 2016. Results are available in $\mathrm{CO}_{2}$ eq. only, as the referenced studies focused on carbon footprints. 


\section{Results}

The following sections present results for global warming (Section 4.1), the entire environmental profile (Section 4.2), and the contribution of life cycle stages (Section 4.3).

\subsection{Global Warming ( $\mathrm{CO}_{2}$ eq.)}

Results show a total of 14,686 kt CO 2 eq. for Vienna's 2016 baseline (Figure 4). This equals approximately $8 \mathrm{t} \mathrm{CO}_{2}$ eq. per capita. Over one half (53\%) of city-wide GHG emissions can either directly or indirectly be attributed to the local government (up to level $3 a)$. The other half $(47 \%)$ is beyond governmental responsibilities (level 3b). Within level $3 \mathrm{~b}$, food and goods consumption account for the largest parts (91\%). Freight transport, industry, and agriculture account for the rest ( $9 \%$ of level $3 \mathrm{~b})$.
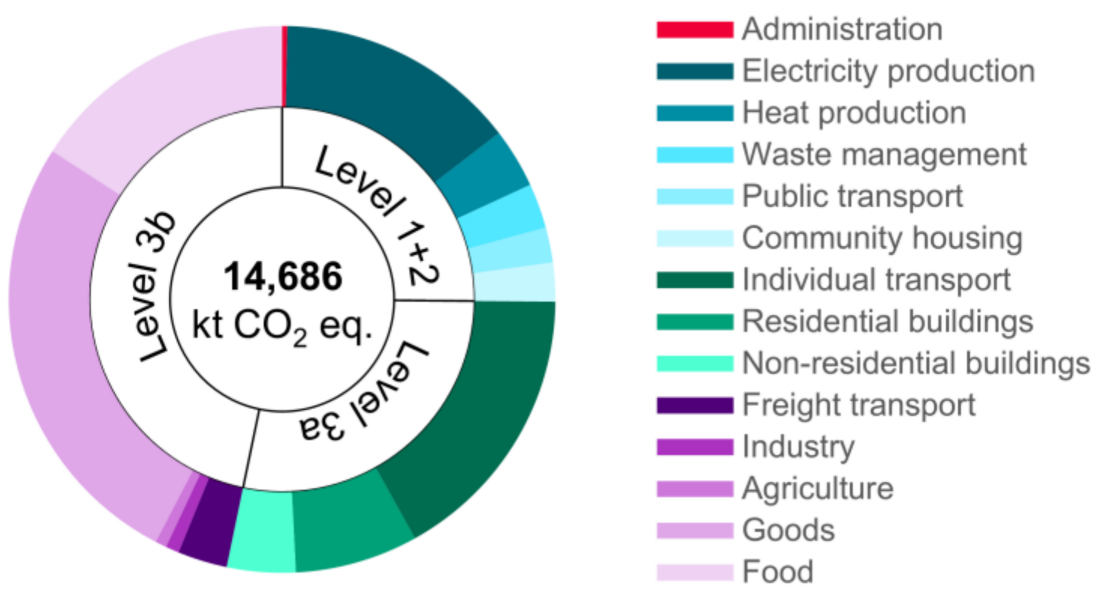

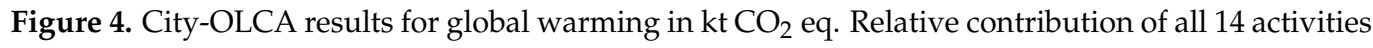
according to the assessment levels defined in Figure 2. Levels 1+2, 3a, and $3 \mathrm{~b}$ account for 25\%, 28\%, and $47 \%$, respectively.

Approximately 25\% of city-wide emissions are caused by the city's own operations (level 1 and 2). This includes the administration itself, energy provision, public transport, waste management, and community housing. The remaining $28 \%$ in level 3a are buildingand transport-related.

The city is the largest electricity provider and produces nearly $80 \%$ of the total electricity consumed in Vienna. Its grid mix emission factor of $420 \mathrm{~g} \mathrm{CO}_{2}$ eq. $/ \mathrm{kWh}$ is slightly higher than the national average. This is mainly due to Vienna's high share of gas fired power plants.

\subsection{Environmental Impacts beyond Climate Change (Environmental Profile)}

The city of Vienna causes environmental burdens beyond greenhouse gases. We chose 11 additional impact categories to account for some of these burdens. Table 2 shows the absolute values for all impact categories considered.

The contribution of activities in their respective assessment level to the total result is displayed in Figure 5. These values are presented without food and goods consumption, as data for those activities were not available. For comparison reasons, global warming is displayed accordingly. 
Table 2. City-OLCA's impact assessment results for Vienna's 2016 baseline in absolute values.

\begin{tabular}{ccc}
\hline Impact Category & Unit & Value \\
\hline Global warming & $\mathrm{kg} \mathrm{CO}_{2}$ eq. & $1.47 \times 10^{10}$ \\
Stratospheric ozone depletion & $\mathrm{kg} \mathrm{CFC-11} \mathrm{eq.}$ & $6.80 \times 10^{3}$ \\
Ionizing radiation & $\mathrm{kBq} \mathrm{Co-60} \mathrm{eq.}$ & $7.01 \times 10^{8}$ \\
Ozone formation, human health & $\mathrm{kg} \mathrm{NO}$ eq. & $1.58 \times 10^{7}$ \\
Fine particulate matter formation & $\mathrm{kg} \mathrm{PM}$ P $_{2.5}$ eq. & $7.40 \times 10^{6}$ \\
Ozone formation, Terrestrial ecosystems & $\mathrm{kg} \mathrm{NO}$ eq. & $1.64 \times 10^{7}$ \\
Terrestrial acidification & $\mathrm{kg} \mathrm{SO}$ eq. & $1.80 \times 10^{7}$ \\
Marine eutrophication & $\mathrm{kg} \mathrm{N}-\mathrm{eq}$. & $3.10 \times 10^{5}$ \\
Freshwater ecotoxicity & $\mathrm{kg} \mathrm{1,4-DCB}$ & $4.82 \times 10^{8}$ \\
Human carcinogenic toxicity & $\mathrm{kg} 1,4-\mathrm{DCB}$ & $1.90 \times 10^{10}$ \\
Mineral resource scarcity & $\mathrm{kg} \mathrm{Cu}$ eq. & $2.37 \times 10^{7}$ \\
Fossil resource scarcity & $\mathrm{kg}$ oil eq. & $2.96 \times 10^{9}$ \\
\hline
\end{tabular}
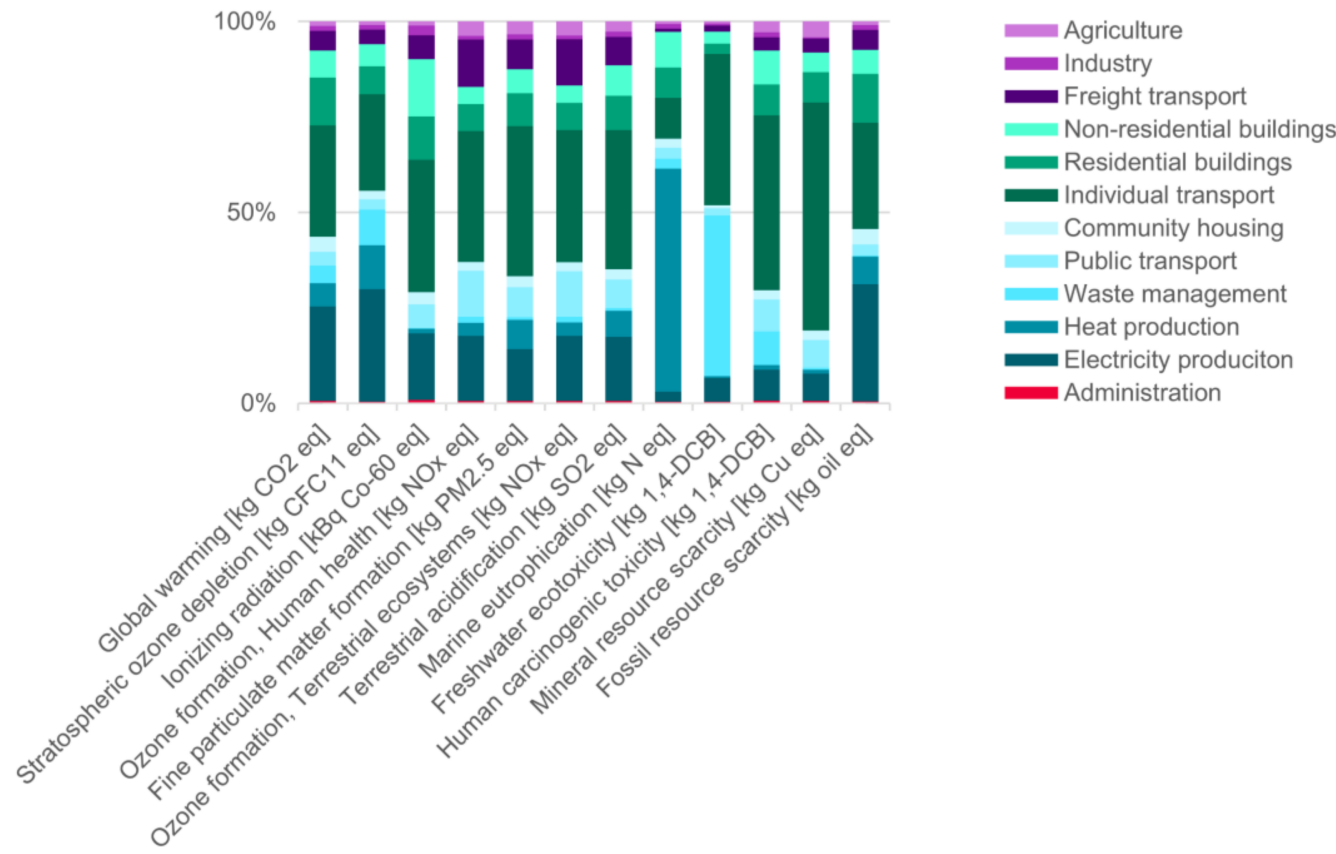

Figure 5. Environmental profile of Vienna according to city-OLCA. For comparison reasons, relative contribution of activities is displayed without food and goods consumption.

In general, individual transportation and electricity production dominate most impact categories. Compared to the global warming distribution, the contribution of activities among additional impacts varies in magnitude. Ozone depletion, marine eutrophication, and freshwater ecotoxicity are determined $(>50 \%)$ by the city's public service provision (level 1). These categories show significant contributions of electricity production (29\%), heat production $(58 \%)$, and waste management $(42 \%)$, respectively.

The other categories are dominated by activities beyond public service provision and most of them by level 3a. Terrestrial ecotoxicity shows a $29 \%$ contribution of freight transportation, which is the highest among all impact categories. For the rest, level $3 \mathrm{~b}$ impacts are all below $17 \%$.

\subsection{Contribution of Life Cycle Stages}

So far, the contribution of city activities on different impact categories were presented. We also investigated the contribution of processes causing these impacts.

Regarding global warming, all activities are driven by the operational stage (usephase). The supply with electricity and heat or the burning of fuels "outperform" embodied 
emissions from the production stage. Two examples shall be representative here. Taking all building types together, emissions from producing the buildings amount to approximately $159 \mathrm{kt} \mathrm{CO}_{2}$ eq. (or $8 \%$, respectively). Emissions from the production of passenger cars for individual transportation (in Figure 6a) amount to approximately $553 \mathrm{kt} \mathrm{CO}_{2}$ eq. (or $21 \%$, respectively). However, the dominating stage shifts with different impact categories.

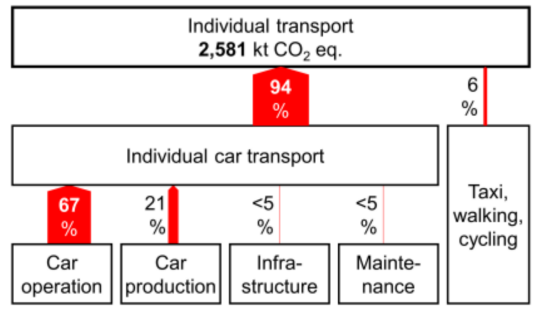

(a)

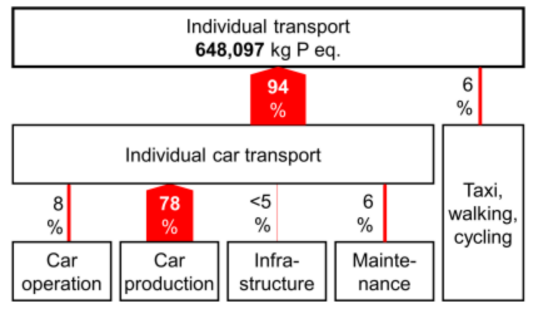

(b)

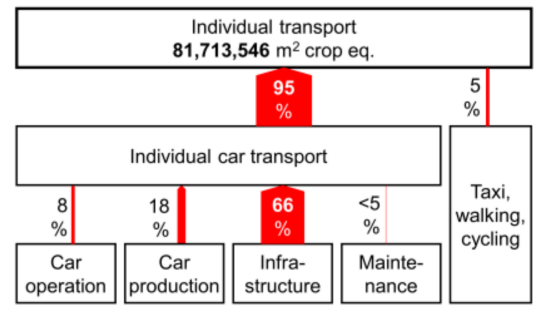

(c)

Figure 6. Individual transportation process contribution (driver tree) for (a) global warming, (b) freshwater eutrophication, and (c) land use. Width of red arrow shows relative contribution to the respective indicator. A hotspot shift from the operation of cars (in $\mathbf{a})$ to the production of cars (in $\mathbf{b}$ ) and to the production of infrastructure (in c) is clearly visible.

When looking at freshwater eutrophication (Figure 6b), operating a car is marginal compared to producing it. Here, car production takes the lead with almost $78 \%$. On the other hand, land use is clearly driven by the infrastructure needed (in Figure 6c). This hotspot shift among impact categories can be found among all activities.

\section{Discussion}

We discuss Vienna specific case study findings in Section 5.1 and city-OLCA related methodological findings in Sections 5.2 and 5.3. Remarks on the transferability to and feasibility of city-OLCA for other cities are given in Section 5.4.

\subsection{Case Study Vienna}

Our results are $43 \%$ higher than the national GHG inventory for Vienna (BLI) [15] and $67 \%$ higher than Vienna's own GHG monitoring scheme (KliP) [14]. For better comparison, we grouped the city-OLCA activities according to the sectors covered in both references (Figure 7). Especially food and goods consumption cause city-OLCA results to exceed the references by up to a factor of 3 .

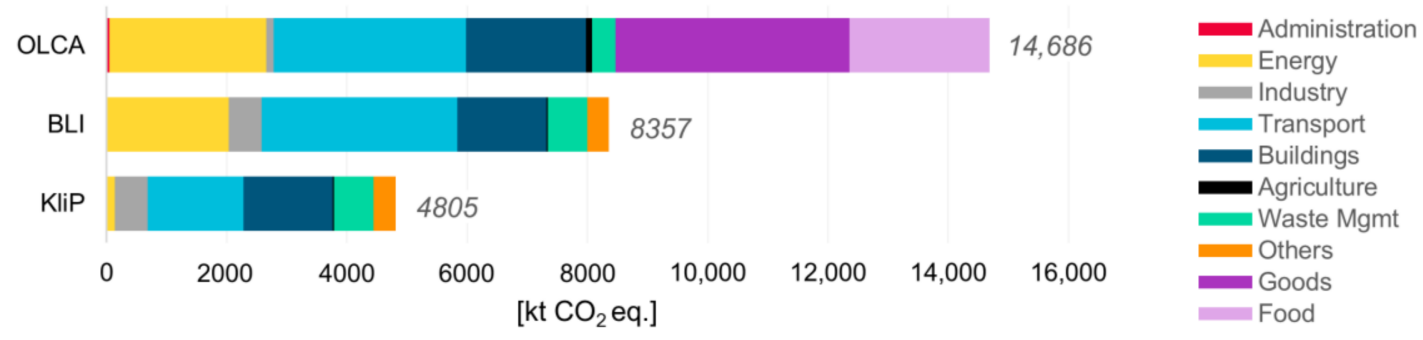

Figure 7. City-OLCA results in comparison with reported values from the national breakdown for Vienna (BLI) and Vienna's own monitoring scheme (KliP). Activities are grouped to match the sectors from both reference documents. Values are given in $\mathrm{kt} \mathrm{CO}_{2}$ eq. and were taken from $[3,4]$.

BLI and KliP include the sectors according to the UNFCCC reporting principles [36] with the same data basis but differ in calculation principles. KliP does not account for energy producers bound to the European trading scheme (ETS) and only recognizes domestic transportation. The remaining sectors are adopted from BLI [14]. The reason for KliP excluding ETS energy producers is the city's missing leverage power to further reduce greenhouse gas emissions from this sector [14]. Considering impacts beyond global 
warming does not support this rationale anymore. Therefore, city-OLCA includes all energy providers.

We expected our results to be higher than the reference studies. This has three main reasons, as city-OLCA

1. Includes food and goods consumption;

2. Calculates $\mathrm{CO}_{2}$ eq. based on all greenhouse gases;

3. Follows a life cycle approach;

Extending the assessment scope with additional activities certainly leads to higher emissions. Even without the latter, more characterized greenhouse gases cause higher emissions. For example, BLI only accounts for $\mathrm{CO}_{2}, \mathrm{CH}_{4}$ and $\mathrm{N}_{2} \mathrm{O}$ [15], while our results include greenhouse gases like several chloro- or bromocarbons. This effect is, however, small, since only a few additional greenhouse gases have been inventoried. Considering more than one life cycle stage shows that embodied emissions are responsible for higher environmental impacts and can lead to hotspot shifts among the entire environmental profile. A last effect is the data themselves. We aimed at getting as many detailed data as possible, not trying to reproduce the BLI but to come up with an unbiased city-OLCA framework modeled in SimaPro. There are certainly gaps in precision or simply unknown data backgrounds. Some sectors might appear to have smaller impacts in city-OLCA (e.g., industry), while in fact data on point sources from factories were unavailable to us. For transparency reasons, we did not fill such data gaps with the reported $\mathrm{CO}_{2}$ eq. value (also because this would not give us any advantages for other impact categories). We can be fairly certain that city-OLCA produces considerably higher results than BLI and KliP if the data background were exactly the same.

For Vienna, this has implications on the effect of reduction measures. In our example, car travel covers half of the transport demand, but it induces $88 \%$ of transport-related emissions. The other half is covered by alternative modes that induce $12 \%$ of transportrelated emissions (public transport, walking, cycling). From a level 3a perspective, a modal shift toward other modes would target $31 \%$ of overall emissions (share of car travel). However, from a level $3 \mathrm{~b}$ perspective, it would only target some $17 \%$.

Even without taking consumption into account, focusing on global warming only generates environmental blind spots (see Figures 5 and 6). While Vienna would target transport from a global warming perspective, its leverage power to reduce ozone depletion might lie in its own hands. The city-OLCA framework can help to identify these hotspots and to prioritize mitigation measures.

\subsection{Methodological Findings I: Energy Modeling Perspectives Change Mitigation Target Sectors}

City-OLCA aims at measuring the environmental performance of a city from an organizational perspective. This perspective resulted in attributing all energy produced by the city to the city administration. As the amount of produced energy at city level does not match energy consumption of the city, energy-related emissions are distributed in several sectors. Part of the energy-related emissions in the city is located at the production side, while part of it is located at the consumption side (see a in Figure 8).

As Vienna produces a lot of electricity, it has also a significant contribution to the country's electricity production (Section 3.1.1). This accounting approach comes with some challenges in modeling, as the remaining part of the energy consumption must be modeled additionally. Vienna's energy production was subtracted from the national grid that is connected to the consumption side.

Another possibility would be to allocate all energy to the respecting consuming sectors, taking only the Austrian average grid mix (see Figure 8b). From an accounting perspective, this approach leads to the same total result. 


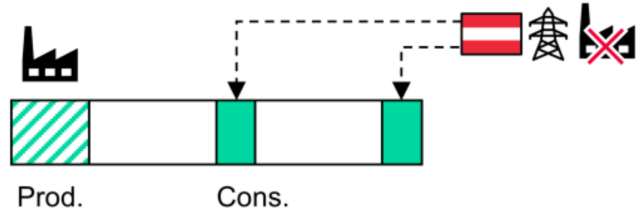

(a)

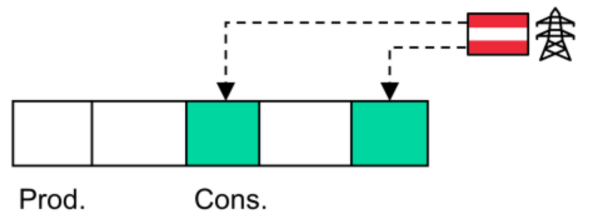

(b)

Figure 8. Energy modeling perspectives: (a) production and consumption approach, where part of energy-related emissions in the city is attributed to city producers (prod.), while the remaining part is attributed to consumers (cons.). (b) Consumption-only approach, where all energy-related emissions are attributed to the consumption side. Both approaches lead to the same total result but have different implications on mitigation measures.

Both approaches would be possible. However, the consumption-based approach loses the organizational perspective and influence on the city level in energy generation, whereas the production- and consumption-based approach does not consider the demand side, which triggers the production of energy in the first place. Hence, these two perspectives lead to different conclusions when it comes to mitigation measures.

In a production- and consumption-based approach, city administration is incentivized to change its energy production mix (fuel switch) or implement modern power plants. In a consumption-based approach, the city administration is incentivized to increase, for example, building efficiency (by introducing stricter building codes).

\subsection{Methodological Findings II: Life Cycle Stages Logic Suitable for City-OLCA}

The previous version of city-OLCA required a distinction between indirect upstream, direct, and indirect downstream activities [13]. This has its roots in the corporate nature of OLCA. The use of a sold product would represent an indirect downstream activity, while the production would be a direct activity. From a city's point of view, we no longer see this logic to bring any meaningful information when it comes to mitigation strategies. Thus, in this paper, we followed the classic life cycle stages logic.

\subsection{Methodological Findings III: Data Availability Considered Good}

Vienna follows an exceptional data excellence strategy. On the platform data.gv.at, the administration makes city-related data publicly available (accompanied by comprehensive reports referenced in Section 3). This verified Open Government Data (OGD) should enable individuals or companies to develop applications that increase the quality of life in Vienna [37], and it helped us in acquiring the necessary data for this work. Overall data availability for Vienna is considered good.

To cover a broad spectrum of city activities, we also related them to time-use data (Section 3.6). These data proved to be a valuable addition to classic activity data such as transport demand. This way, we were able to estimate the impact of food and goods consumption on global warming. The impact beyond global warming is still unknown.

We assume food and goods consumption to have a significant impact on other categories as well, given its high effect on global warming. However, the environmental profile of different impact categories varies, as was shown in Section 4.2. Where to expect a hotspot shift regarding food and goods consumption remains to be investigated.

\subsection{Transferability and Feasibility}

Our results appear well supported by what is frequently discovered in LCA research compared to conventional approaches:

- Underestimating environmental burdens;

- Having blind spots regarding a diverse set of environmental indicators.

This was true for Vienna and will be for other cities that monitor their emissions based on the UNFCCC reporting sector rules (see [36]). As these rules were originally intended for national inventories, some cities might consider the community scale greenhouse 
gas protocol (GPC) as the monitoring basis (see [38]). Toronto, for example, reports its greenhouse gas emissions since 1990 based on the GPC [39]. However, upstream emissions are not mandatory, and neither are food and goods consumption. Additionally, to the best of our knowledge, no current city environmental assessment scheme considers the degree of influence as is reflected by the four assessment levels proposed in city-OLCA.

Based on our observations, we encourage city managers to include level $3 \mathrm{~b}$ activities in their mitigation strategies, either in finding ways to transfer them into lower assessment levels (and make them therefore more controllable), or by directly addressing them in informational campaigns and targeting a considerable share of environmental impacts. The specific design of measures is subject to the city's capabilities and its decision-makers, respectively.

Applying city-OLCA to Vienna proved feasible. High data availability contributed substantially to this. Other cities with an accounting scheme in place will certainly profit from having acquired basic information such as transport demand or energy consumption. However, city-OLCA has also pointed out additional data needs (food and goods consumption). Here, cities (or countries) that perform time-use surveys can utilize them to overcome data gaps. The center for time-use research publishes multinational time use surveys [40], which might be of particular interest for other city cases.

\section{Conclusions}

This work has demonstrated a successful first application of city-OLCA with real city data on the example of Vienna. The overall city-OLCA framework proved applicable and could represent the situation in Vienna.

Our results indicate that $47 \%$ of greenhouse gas emissions are beyond direct governmental responsibilities. This should encourage local governments to find ways to address a large share that is often underestimated by conventional approaches. When aiming at conventional reduction measures, it must be noted that a considerable portion of environmental impact might not be affected by these measures.

While city-OLCA supports local governments in environmental performance tracking and in prioritizing mitigation measures, it does not assess the feasibility of the measures itself. Installing a modern power plant, switching to alternative fuels, or launching an informational campaign must also be economically viable and may even depend on a political agenda. However, it becomes apparent that external pressures to reduce emissions grow (e.g., Fridays for future), which may also force city managers to act faster. Understanding environmental impacts from an organizational perspective could be helpful in managing emissions on a more practical basis with the background of an ISO-recognized scientific method (OLCA) [17].

City-OLCA is not intended for city comparisons. The reporting unit (the functional unit equivalent in product LCA) acknowledges the heterogeneity of public services that are provided in the city. It does not allow for comparative assertions of services provided in other cities. To make them comparable, the quality of each service would have to be assessed by including a quality constraint into the reporting flow (e.g., delays of bus rounds allowed or substance limits in waste treatment residues) [13]. Although this might, in theory, be possible, we believe it to exceed complexity for this study.

City-OLCA was found to be a promising approach for environmental decision support in cities and its method a valuable contribution to the research field of urban sustainability. Further work on time-use studies beyond global warming would help to explore cityOLCA's full potential. We also hope that our research will serve as a basis for future case studies to establish a deeper understanding in similarities and differences among city structures and their implications on performing city-OLCA. 
Supplementary Materials: The following are available online at https: / www.mdpi.com/article/ 10.3390/su13095062/s1, Figure S1: Overview of parameterized SimaPro city model driver tree for global warming with cut-off $<0.18 \%$. Section A, B, and C displayed in detail in Figures S2, S3, and S4, respectively. Food and goods consumption not included. Figure S2: Section view "A" of Figure S1, displaying details for electricity production, district heat production, waste management, freight transport, and in-dividual transport. Figure S3: Section view "B" of Figure S1, displaying details for public transport. Figure S4: Section view "C" of Figure S1, displaying details for administration, industry, residential buildings, community housing, non-residential buildings, building production (aggregated), and agriculture. Figure S5: District heating mix in Vienna for 2016. Figure S6: Heating mixes in buildings without district heating for (a) residential buildings, (b) non-residential buildings, and (c) administrative and community housing buildings. Figure S7: Waste treatment pathways.

Author Contributions: Conceptualization, A.C., M.B. and M.F.; methodology, A.C.; software, A.C.; validation, K.M., M.B. and M.F.; formal analysis, A.C.; investigation, A.C.; data curation, A.C.; writing-original draft preparation, A.C.; writing—review and editing, K.M., M.B. and M.F.; visualization, A.C.; supervision, K.M. and M.B.; project administration, A.C. All authors have read and agreed to the published version of the manuscript.

Funding: This research received no external funding.

Institutional Review Board Statement: Not applicable.

Informed Consent Statement: Not applicable.

Data Availability Statement: Not applicable.

Conflicts of Interest: The authors declare no conflict of interest.

\section{Appendix A}

Table A1. List of important abbreviations (reported alphabetically).

\begin{tabular}{cc}
\hline Abbreviation & Definition \\
BLI & $\begin{array}{c}\text { Austria's greenhouse gas monitoring scheme as reported in the } \\
\text { Austrian federal air pollution inventory } \\
\text { CHP }\end{array}$ \\
eq. & $\begin{array}{c}\text { German: Bundesluftschadstoffinventur) } \\
\text { Combined heat and power } \\
\text { ETS }\end{array}$ \\
GHG & Equivalents \\
GPC & Greenhouse gas \\
ISO & Global protocol on community-scale greenhouse gas accounting \\
KliP & International organization for standardization \\
LCA & Vienna's greenhouse gas monitoring scheme as reported in the \\
climate program (German: Klimaprogramm) & Life cycle assessment \\
OGD & Multi-region input-output \\
OLCA & Open government data \\
UNFCCC & Organizational life cycle assessment \\
\hline
\end{tabular}

\section{References}

1. Kennedy, C.; Baker, L.; Dhakal, S.; Ramaswami, A. Sustainable Urban Systems. J. Ind. Ecol. 2012, 16, 775-779. [CrossRef]

2. United Nations Pupulation Fund-Urbanization. Available online: https://www.unfpa.org/urbanization (accessed on 16 April 2021).

3. Rosenzweig, C.; Solecki, W.; Romero-Lankao, P.; Mehrotra, S.; Dhakal, S.; Bowman, T.; Ali Ibrahim, S. ARC3.2 Summary for City Leaders. Urban Climate Change Research Network; Columbia University: New York, NY, USA, 2015.

4. Currie, P.K.; Musango, J.K.; May, N.D. Urban metabolism: A review with reference to Cape Town. Cities 2017, 70, 91-110. [CrossRef]

5. Lugaric, L.; Krajcar, S. Transforming cities towards sustainable low-carbon energy systems using emergy synthesis for support in decision making. Energy Policy 2016, 98, 471-482. [CrossRef] 
6. Lombardi, M.; Laiola, E.; Tricase, C.; Rana, R. Assessing the urban carbon footprint: An overview. Environ. Impact Assess. Rev. 2017, 66, 43-52. [CrossRef]

7. Geng, Y.; Zhang, L.; Chen, X.; Xue, B.; Fujita, T.; Dong, H. Urban ecological footprint analysis: A comparative study between Shenyang in China and Kawasaki in Japan. J. Clean. Prod. 2014, 75, 130-142. [CrossRef]

8. Beloin-Saint-Pierre, D.; Rugani, B.; Lasvaux, S.; Mailhac, A.; Popovici, E.; Sibiude, G.; Benetto, E.; Schiopu, N. A review of urban metabolism studies to identify key methodological choices for future harmonization and implementation. J. Clean. Prod. 2016, 163, S223-S240. [CrossRef]

9. Dong, H.; Fujita, T.; Geng, Y.; Dong, L.; Ohnishi, S.; Sun, L.; Dou, Y.; Fujii, M. A review on eco-city evaluation methods and highlights for integration. Ecol. Indic. 2016, 60, 1184-1191. [CrossRef]

10. Yetano Roche, M.; Lechtenböhmer, S.; Fischedick, M.; Gröne, M.-C.; Xia, C.; Dienst, C. Concepts and Methodologies for Measuring the Sustainability of Cities. Annu. Rev. Environ. Resour. 2014, 39, 519-547. [CrossRef]

11. Mirabella, N.; Allacker, K.; Sala, S. Current trends and limitations of life cycle assessment applied to the urban scale: Critical analysis and review of selected literature. Int. J. Life Cycle Assess. 2018, 20, 3. [CrossRef]

12. Albertí, J.; Brodhag, C.; Fullana-I-Palmer, P. First steps in life cycle assessments of cities with a sustainability perspective: A proposal for goal, function, functional unit, and reference flow. Sci. Total Environ. 2019, 646, 1516-1527. [CrossRef] [PubMed]

13. Cremer, A.; Müller, K.; Berger, M.; Finkbeiner, M. A framework for environmental decision support in cities incorporating organizational LCA. Int. J. Life Cycle Assess. 2020, 25, 2204-2216. [CrossRef]

14. Holzmann, A.; Knaus, K.; Siebenhofer, M. Fortschrittsbericht über die Umsetzung des Klimaschutzprogramms (KliP) der Stadt Wien; Austrian Energy Agency: Vienna, Austria, 2019.

15. Anderl, M.; Gangl, M.; Haider, S.; Ibesich, N.; Lampert, C.; Poupa, S.; Purzner, M.; Schieder, W.; Schodl, B.; Titz, M.; et al. Bundesländer Luftschadstoff-Inventur 1990-2018. In Regionalisierung der nationalen Emissionsdaten auf Grundlage von EU-Berichtspflichten (Datenstand 2019); Umweltbundesamt (UBA): Vienna, Austria, 2019.

16. Vienna Tops Mercer's 21st Quality of Living Ranking. Available online: https://www.mercer.com/newsroom/2019-quality-ofliving-survey.html (accessed on 23 February 2021).

17. ISO, ISO/TS 14072: Environmental Management_Life Cycle Assessment-Requirements and Guidelines for Organizational Life Cycle Assessment; International Organization for Standardization (ISO): Geneva, Switzerland, 2014.

18. Pollak, P. Energiemanagement von Objekten der Stadt Wien; Stadtrechnungshof Wien: Vienna, Austria, 2017.

19. Prahler, C.; Simander, G. Bericht Über den Jährlichen Energieverbrauch in Erfassten Gebäuden Gemäß § 23 Abs. 4 EEffG; Austrian Energy Agency: Vienna, Austria, 2017.

20. Vogl, B.; Ritter, H.; Watzak-Helmer, M.; Cerveny, M.; Schmid, W.; Valuch, M. Energie! Voraus—Energiebericht der Stadt Wien (Daten 2016); Magistrat der Stadt Wien: Vienna, Austria, 2018.

21. Gollner, M. Energiedaten Österreich 2016; Statistik Austria: Vienna, Austria, 2017.

22. Vogl, B.; Geier, S.; Kinsperger, A.; Hemis, H.; Dabringer, M.; Grgic, K.; Reisenbichler, M.; Emrich, H.; Huber, D.; Vlay, B.; et al. Fachkonzept Energieraumplanung-STEP 2025; Magistratsabteilung 20-Energieraumplanung: Vienna, Austria, 2019.

23. Virág, D. Das Verkehrssystem im Stock-Flow-Nexus. In Analyse der Materialbestände und-Flüsse für Verschiedene Formen von Mobilität in Wien; Social Ecology Working Paper 179; Institute of Social Ecology: Vienna, Austria, 2019.

24. BMVIT. Ergebnisbericht zur Österreichweiten Mobilitätserhebung "Österreich unterwegs 2013/2014"; Bundesministerium für Verkehr, Innovation und Technologie (BMVIT): Vienna, Austria, 2016.

25. Heidinger, K.; Verdis, S.; Wandaller, P. Vienna 2025-Comparing the Benefits of Vienna's Infrastructure Choices; Siemens: London, UK, 2014.

26. Egle, L.; Rolland, C.; Broukal, S. Ist-Zustand der Wiener Abfallwirtschaft 2017 (Langfassung); Magistratsabteilung 48-Abfallwirtschaft Straßenreinigung und Fuhrpark: Vienna, Austria, 2017.

27. BMNT. Die Bestandsaufnahme der Abfallwirtschaft in Österreich. Statusbericht 2018; Bundesministerium für Nachhaltigkeit und Tourismus (BMNT): Vienna, Austria, 2018.

28. Über Wiener Wohnen. Available online: https://www.wienerwohnen.at/ueber-uns/ueber.html (accessed on 25 February 2021).

29. Smetschka, B.; Wiedenhofer, D.; Egger, C.; Haselsteiner, E.; Moran, D.; Gaube, V. Time matters: The carbon footprint of everyday activities in Austria. Ecol. Econ. 2019, 164, 106357. [CrossRef] [PubMed]

30. Schmid, F. Vienna's GHG Emissions from a Production vs. Consumption-Based Accounting Perspective: A comparative Analysis; Social Ecology Working Paper 183; Institute of Social Ecology: Vienna, Austria, 2020.

31. Huijbregts, M.A.J.; Steinmann, Z.J.N.; Elshout, P.M.F.; Stam, G.; Verones, F.; Vieira, M.D.M.; Hollander, A.; Zijp, M.; vsn Zelm, R. ReCiPe 2016-A Harmonized Life Cycle Impact Assessment Method at Midpoint and Endpoint Level; National Institute for Public Health and the Environment: Bilthoven, The Netherlands, 2016.

32. SimaPro-LCA Software for Fact-Based Sustainability. Available online: https://simapro.com/ (accessed on 16 April 2021).

33. Ecoinvent 3.4. Available online: https://www.ecoinvent.org/database/older-versions/ecoinvent-34/ecoinvent-34.html (accessed on 16 April 2021).

34. Emami, N.; Heinonen, J.; Marteinsson, B.; Säynäjoki, A.; Junnonen, J.-H.; Laine, J.; Junnila, S. A life cycle assessment of two residential buildings using two different LCA database-software combinations: Recognizing uniformities and inconsistencies. Buildings 2019, 9, 20. [CrossRef]

35. The Eora Global Supply Chain Database. Available online: https://www.worldmrio.com (accessed on 16 April 2021). 
36. UNFCCC Reporting Requirements. Available online: https://unfccc.int/process-and-meetings/transparency-and-reporting/ reporting-and-review-under-the-convention/greenhouse-gas-inventories-annex-i-parties/reporting-requirements (accessed on 16 April 2021).

37. DigitalesWien-Was is OGT? Available online: https://digitales.wien.gv.at/open-data/ (accessed on 23 February 2021).

38. Fong, W.K.; Sotos, M.; Doust, M.; Schultz, S.; Marques, A.; Deng-Beck, C. Global Protocol for Community-Scale Greenhouse Gas Emission Inventories: An Accounting and Reporting Standard for Cities; World Resources Institute: Washington, DC, USA; Canadian Electronic Library: Ottawa, ON, Canada, 2015.

39. Toronto's 2018 Greenhouse Gas Emissions Inventory. Available online: https://www.toronto.ca/services-payments/waterenvironment/environmentally-friendly-city-initiatives/transformto/torontos-greenhouse-gas-inventory/ (accessed on 16 April 2021).

40. Multinational Time Use Study. Available online: https://www.timeuse.org/mtus (accessed on 23 February 2021). 